MATEC Web of Conferences 22,03003 (2015)

DOI: $10.1051 /$ matecconf/ 20152203003

(C) Owned by the authors, published by EDP Sciences, 2015

\title{
A Space Cam Mechanism for Power Transmission of an Oppo- site-cylinder Piston Engine
}

\author{
Haoyue Zhang*, Xiaojun Xu, Lei Zhang, Faliang Zhou \\ College of Mechatronics Engineering and Automation, National University of Defense Technology, Changsha, \\ Hunan, China
}

\begin{abstract}
For the purpose of improving the engine's power density, we put forward a new type of power transmission mechanism which is used for opposed-cylinder engine. The gas pressure acts on the cam through the piston and push rod, and the spindle rotation of external is driven by the cam. The design of spatial cam work surface is completed by using the enveloping theory of a family of space curves, the force between roller and cam is analyzed using dynamic analysis software. Under the condition of equal number, size and stroke of piston, the new one with larger power density is more compact in structure than the traditional power transmission mechanism, and the reaction force on either side of the main shaft and the acting force between pistons and cylinders are smaller than those in traditional one, which prolongs the service life of the pistons.
\end{abstract}

Keywords: power transmission; space cam; supercharge; stress

\section{INTRODUCTION}

The special space mechanism internal combustion engine has been widely applied in military fields, and familiar ones are cam-type, swash plate-type and wobble plate-type (Peng et al. 2007, Yongqing et al. 2011). The roller mounted at the bottom of push rod of cam engine can effectively improve the wear and tear. For the mechanism, the piston motion is easy to control; the operation is stable; the structure is compact and combined with the application of advanced hardware and software technology; and cam engine research has important practical significance.

Existing admission and exhaust system of cam engines are complex, and increasing engine power by means of inlet pressure (Hougeng 2004) needs extra supercharger. Having drawn lessons from the workings of a two-stroke internal combustion engine, a part of energy which is from the work of combustible gas is used to improve the engine inlet pressure, which can make the overall structure of the engine more compact.

The power transmission presented in this article, which combines spatial cam mechanism and mechanical pressurization, is used for the mechanical turbocharged engine. We calculate the cam working surface, and establish a dynamic model of the mechanism with the help of software, and then analyze the stress conditions between the cam and the roller. Compared with the crack-link mechanism The novel engine's power density is higher, and its force situation is better.

\section{THE COMPOSITION AND THE PRESSURIZA- TION THEORY OF NOVEL POWER TRANS- MISSION MECHANISM}

New power transmission mechanism transforms the linear motion into the rotation motion using a spatial space cam solid with outer rotor to transfer force and motion. As shown in Figure 1, there are two kinds of the pistons in the mechanism, pressurization pistons and power pistons, which are differed by the function. The diameter of power pistons is smaller, than that of the pressurization pistons. The same pistons are connected by the push rod, and the group of pistons and push rod is shown in Figure 2. There are two rollers on a push rod, which contact with both of the cam surfaces, among which one is connected to the push rod through a pin shaft, and the other is installed on the elastic roller seat, which is also connected with the push rod through a pin shaft.

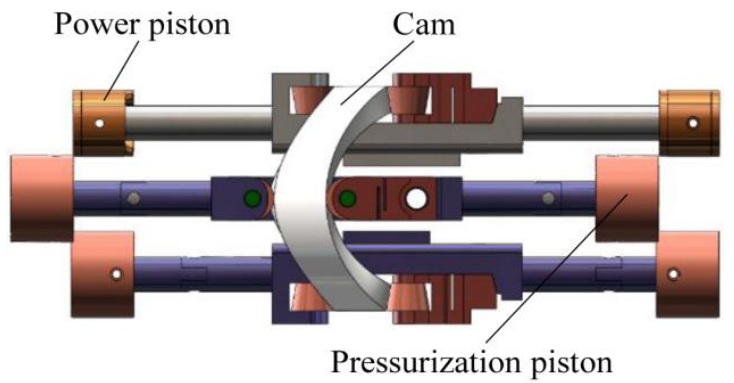

Figure 1. Novel power transmission mechanism

*Corresponding author: 15874924442@163.com

This is an Open Access article distributed under the terms of the Creative Commons Attribution License 4.0, which permits unrestricted use, distribution, and reproduction in any medium, provided the original work is properly cited. 


\section{MATEC Web of Conferences}

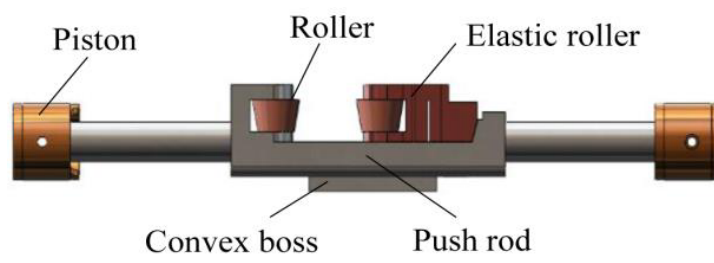

Figure 2. The group of the piston and push rod

New engine adopts two-stroke cycle model, and the power piston rods and the pressurization piston rods are decorated by $90^{\circ}$. The power pistons drive spindle rotate through the push rod, and the spindle transfers rotation and torque, and simultaneously, it drives pressurization piston move. The air in the pressurization cylinder is compressed into the power cylinder through the complex pipeline, which increases the engine inlet pressure(Raman and Ram 2013).

Specific work process is shown in Figure 3, and the reciprocating movement of power piston and pressurization piston is simple harmonic vibration. When power piston is in power stroke, the pipeline between the power cylinder and pressurization cylinder is closed by power piston, and pressurization piston moves down simultaneously. The fast downward speed produces certain vacuum in pressurization cylinder, and the combustible gas is drawn into cylinder. When the power piston is in exhaust stroke, the air in pressurization cylinder is compressed into power cylinder, and completing the pressurization of combustible gas.

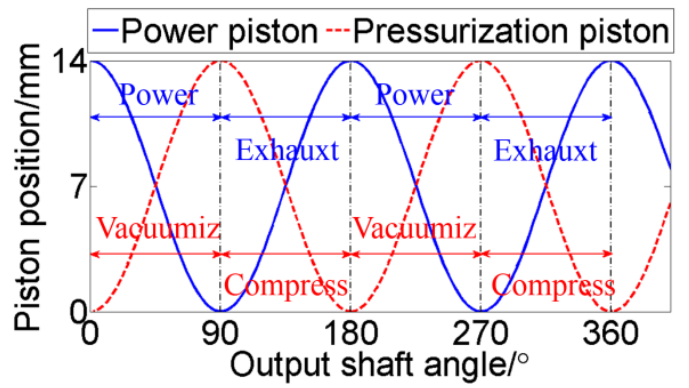

Figure 3. Working process

\section{SOLUTION OF THE CAM WORKING SUR- FACE}

Cam and roller are key parts of the mechanism, and the shape of cam working surface determines the motion of the piston and the realization of the function directly (Xu et al. 2014).

The velocity of the points on the cam radial is different, in order to realize pure rolling between the roller and cam, the rollers are designed into cone. The angle between cone element and the centerline of the roller can be calculated by $\omega_{I}=$ cam angular velocity, $\omega_{2}=$ roller angular velocity, $R_{l}=$ cam outer diameter, and $R_{2}=$ inner diameter. The linear velocity of the cam inner contour line and outer contour line are $v_{11}=\omega_{1} R_{l}$ and $v_{12}=\omega_{1} R_{2}$; radius of roller larger end and the smaller end are $r_{I}$ and $r_{2}$; the linear velocity of the roller larger end and smaller end are $v_{21}=\omega_{2} r_{1}$ and $v_{22}=\omega_{2} r_{2}$. In order to meet the requirements of pure rolling between the cam and the roller, the linear velocity of roller working surface and cam working surface should be equal, namely,

$\left\{\begin{array}{l}v_{11}=v_{21} \\ v_{12}=v_{22}\end{array}\right.$

From the Equation (1) we can get $R_{1} / R_{2}=r_{1} / r_{2}$. The outer diameter and inner diameter of cam are $R_{I}=26 \mathrm{~mm}$ and $R_{I}=20 \mathrm{~mm}$, and $r_{I}=10 \mathrm{~mm}, r_{2}=7.7 \mathrm{~mm}$.

The law of piston motion is

$a=\frac{A}{2} \cos 2 \varphi$

Where $A=$ piston amplitude, $\varphi=$ angle of main shaft Piston works twice during one rotating cycle. The cam working face is the enveloping surface of a family of space curved surfaces whose mother surface is the surface of the roller. The coordinates of cam working surface is calculated according to the moving relationship between cam and roller (Manufacture et al. 2007).

$\vec{r}_{k}=\left[\begin{array}{l}x \\ y \\ z\end{array}\right]=\left[\begin{array}{c}\left(h+h_{0}\right) \cos \varphi+r \sin \alpha \sin \varphi \\ \left(h+h_{0}\right) \sin \varphi-r \sin \alpha \cos \varphi \\ a-r \cos \alpha\end{array}\right]$

Where $x, y$ and $z$ are coordinates of the point on the surface, $\varphi=$ angle of main shaft, which vary continuously from $0^{\circ}$ to $360^{\circ}$, and $h=$ distance between roller smaller end and the cam shaft, and $h_{0}=$ distance between a certain section of roller and its smaller end $r=$ section radius. $a$ is the contact angle of roller and cam. The solution for $a$ uses the envelope condition (Wang and Lin 1989).

$A \frac{\partial x}{\partial \varphi}+B \frac{\partial y}{\partial \varphi}+C \frac{\partial z}{\partial \varphi}=0$

Among them,

$A=\left|\begin{array}{ll}\frac{\partial y}{\partial h} & \frac{\partial z}{\partial h} \\ \frac{\partial y}{\partial \alpha} & \frac{\partial z}{\partial \alpha}\end{array}\right|=r \sin \alpha \sin \beta-r \tan \frac{\pi}{18} \cos \varphi$

$B=\left|\begin{array}{ll}\frac{\partial z}{\partial h} & \frac{\partial x}{\partial h} \\ \frac{\partial z}{\partial \alpha} & \frac{\partial x}{\partial \alpha}\end{array}\right|=-r \sin \alpha \cos \beta-r \tan \frac{\pi}{18} \sin \varphi$

$C=\left|\begin{array}{ll}\frac{\partial x}{\partial h} & \frac{\partial y}{\partial h} \\ \frac{\partial x}{\partial \alpha} & \frac{\partial y}{\partial \alpha}\end{array}\right|=-r \cos \alpha$ 
By solving the Equation (1), we can get the transmission angle between rollers and cam

$$
\tan \alpha=-\frac{2 A \sin 2 \varphi}{h+h_{0}+r \tan \frac{\pi}{18}}
$$

The transmission angle on the whole working surface is shown in Figure 4.

The circle in Figure 4 is the top view of the cam. According to the Equation 6, the transmission angle at the wave crest and wave trough are 0 , but they are the largest on the position A,B,C and D, and that on the inner contour line is greater than the outer.

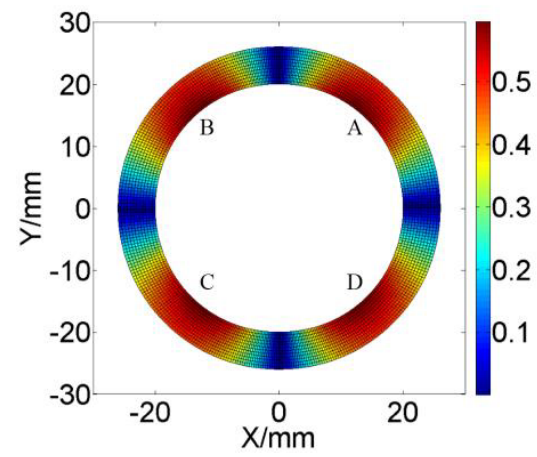

Figure 4. Transmission angle distribution

Considering the structure's strength and stiffness, the parameters of cam and rollers are designed as the value in Table 1.

Table 1. The structural parameters of cam and roller

\begin{tabular}{ll}
\hline Parameters & Value \\
\cline { 2 - 2 } & $\mathrm{mm}$ \\
\hline Cam outer diameter & 52 \\
\hline Cam inner diameter & 40 \\
\hline Cam thickness/mm & 21 \\
\hline Roller smaller end diameter & 15.4 \\
\hline Roller larger end diameter & 20 \\
\hline Roller thickness & 6.5 \\
\hline
\end{tabular}

\section{CHARACTERISTICS ANALYSIS OF THE} NOVEL MECHANISM

\subsection{Comparative analysis mechanism force}

Comparing new power transmission mechanism with the traditional crack-link mechanism, they are same in the number, the diameter and the stroke of piston, and the relevant constraints are defined in the dynamics analysis software to simulate the engine steady working station (Chen et al. 2014), the variation of gas pressure inside the cylinder is shown in Figure 5.

For crack-link mechanism, the piston is under gas pressure $F_{g}$, the force between piston and the connecting rod is $P$, which is used to take torque to the crankshaft, the crankshaft connects the rack through bearings, and the interaction between bearing and crankshaft is $N_{l}$ and $N_{2}$. When the pistons are not on the dead center, they will be under the force $N$ from the cylinders. The crack-link mechanism's force situation is shown in Figure 6. Due to the little quality of the entire mechanism, the influence of gravity is not considered.

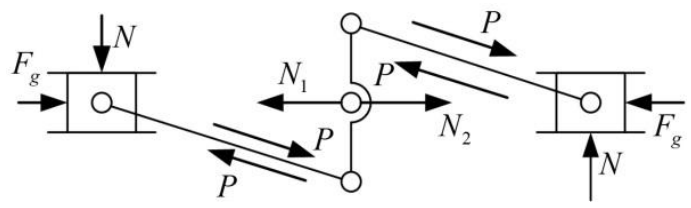

Figure 5. Force analysis of crank-link mechanism

For the novel power transmission mechanism, the pistons are under the gas pressure $F_{g}$ and reactive force $N_{b}$ from the wall of cylinders, the convex bosses of push rods receive support from the rack, and the rollers are under the force $N$ from cam.

In Figure 7, one of the groups of the piston and push rod is selected as a representative, and its force situation is shown. As stated earlier, there are four groups like this, each with two rollers, acting on the both sides of the cam, and the force $N$ on the cam can be resolved into three directions of $x, y, z$. And the cam receives support from the rack. $\alpha$ is the transmission angle, $\beta$ is the roller cone angle.

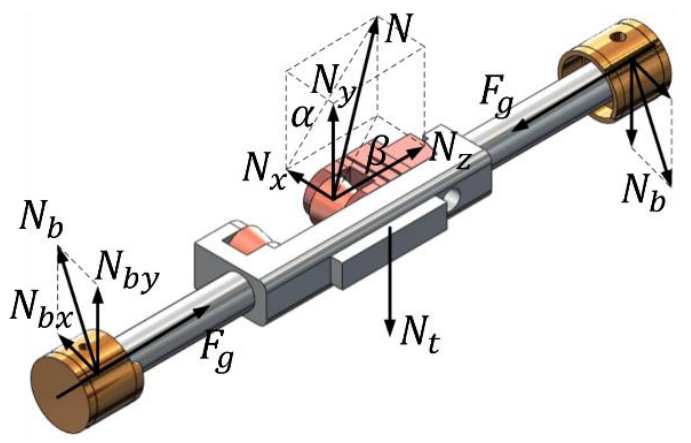

Figure 6. Force analysis of push rod

We can get dynamics of the constraints and components by importing the model into dynamics analysis software (Yongqing et al. 2011).

The main shaft is borne by the spindle bearing on the two ends of it. The force of the either bearing for novel mechanism and crank-link mechanism is shown in Figure 9 and Figure 10. Novel mechanism's working cylinder and pressurization cylinder are twice of the crack-link mechanism, but the force on either side of the main shaft is lower than that of the crack-link mechanism. 


\section{MATEC Web of Conferences}

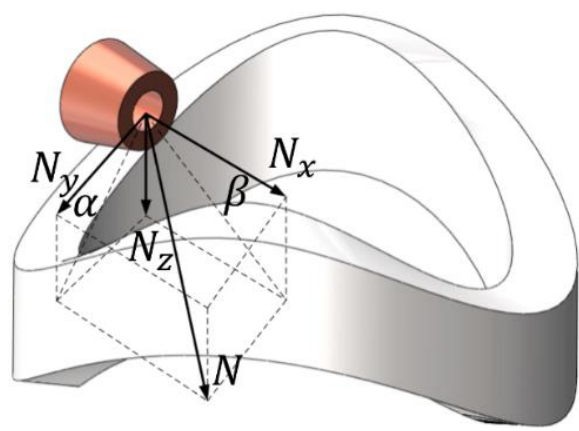

Figure 7 Force analysis of cam

For novel mechanism, the four groups of piston and push rod are circumferential distribution, the angle of position between two of them is $90^{\circ}$. Part of the force on the cam which is from the groups distributed face to face can be offset with each other, and the crack-link mechanism's distribution which is along the axis can't achieve such effect.

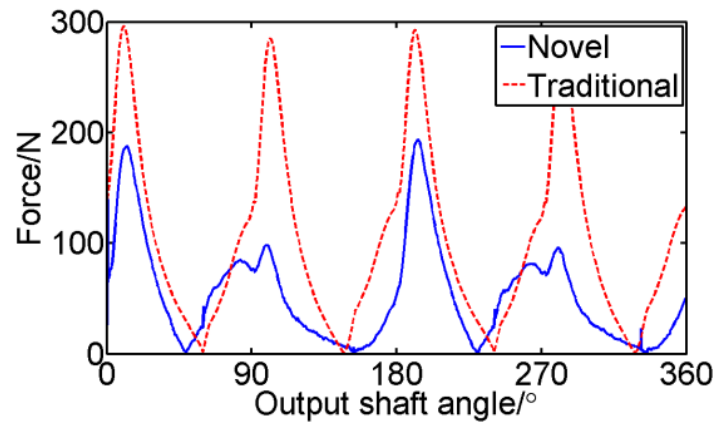

Figure 8. Reaction on the left side of main shaft

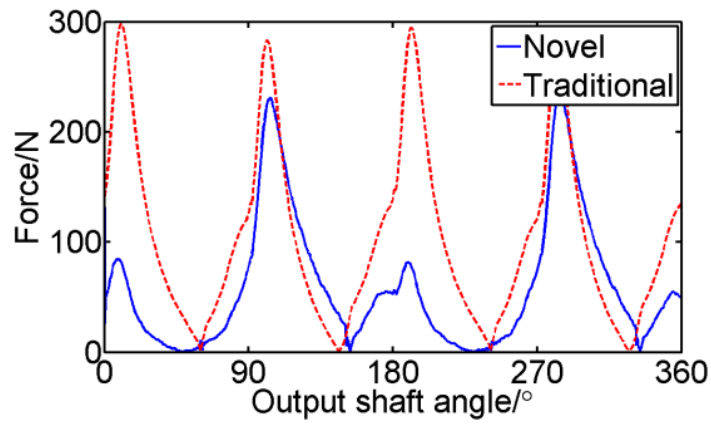

Figure 9. Reaction on the left side of main shaft

The interaction between piston and cylinder affect the wear of piston, so as to affect its service life and seal. Figure 11 shows the simulation results of the force between pistons and cylinders. It is not hard to see that the force between pistons and cylinders in crack-link mechanism is bigger than that in the novel mechanism.

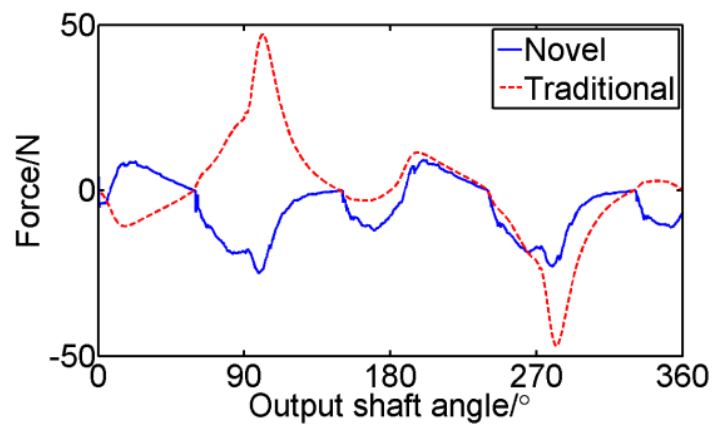

Figure 10. Reaction between the piston and cylinder

The convex boss in middle of the push rod acts as a load bearing structure, as is shows in Figure 12. The structure avoids the push rod rolling and bears the force between piston and cylinder along the cam tangential, which improves the stress state between the pistons and cylinders greatly.

\subsection{Stress analysis}

For novel mechanisms, the interaction between roller and cam is the key to the property (Wang and Lin 1989), and the contact between the cam and the roller is on point or line. As shown in Figure 7 and Figure 8, the interaction force $\mathrm{N}$ between cam and rollers is a complex space force. The contact between the cam and the roller for point or line contact is necessary to analyze the stress between them (Xu et al. 2014).

The stress analysis mentioned before belongs to the coupled transient dynamic problems, and rollers and cam are defined as flexible body, and the rest parts adopt the rigid body. Because the analysis process is complex, the calculation is large, and the mechanism is symmetrical, typically, and the article analyzes one group of power piston and push rod, as shown in Figure 12.

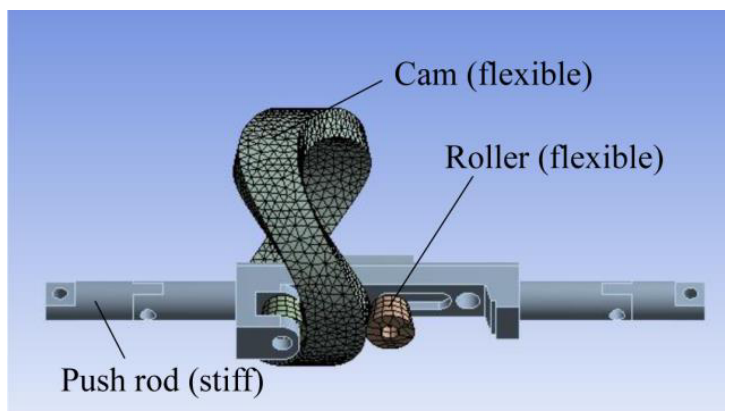

Figure 11 Power push rod group

The analysis lasts $3 \mathrm{~s}$ in the process that the piston is under the explosive force of $360 \mathrm{~N}$ after leaving the upper dead point soon, and the result of equivalent stress is shown in Figure 13 and Figure 14. 
There are several broken lines of the results in Figure 13, followed by force, equivalent stress, normal stress and shear stress. Figure 14 is the equivalent stress nephogram of the roller and cam after $2.5 \mathrm{~s}$. As can be seen from the figure, the maximum stress value is $277.05 \mathrm{MPa}$, based on facts that the materials of the roller and cam are defined as \#45 steel, and the requirements for strength are satisfied. We can increase the strength of the whole structure by choosing better material.

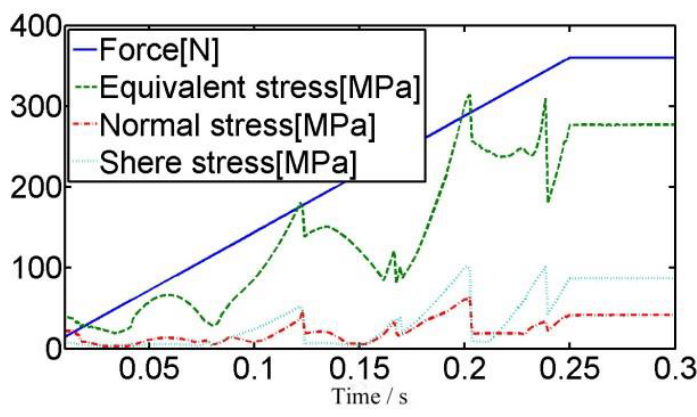

Figure 12. Contact stress

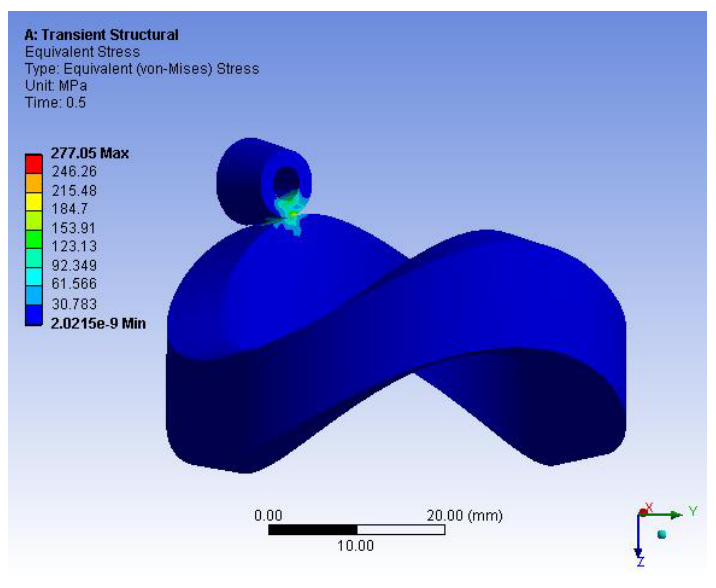

Figure 13. Equivalent stress

\subsection{Power density analysis}

Power transmission characteristics reflects the working ability of mechanism (Zou et al. 2014). The novel power transmission mechanism consists of four power cylinders and four pressurization cylinders, because of the circumferential distribution, the engine is compact in structure. But the size of the crack-link mechanism is bigger for the linear distribution of piston, when the amount of pistons is the same.

Simultaneously, from Figure 3, we can get that in the process of spindle rotation of a circle, the pistons of novel mechanism have two power strokes, twice of that in crank-link mechanism. In fact, the work frequency of novel mechanism is directly proportional to the number of peak valley of cam, if cam is designed into the structure of the "three peaks and valleys", and the amount of pistons power stroke increased to three. The space of improving power density for novel mechanisms is great.

\section{CONCLUSIONS}

The power transmission mechanism proposed by the article is used for opposed-cylinder engine, which combines the working characteristics of cam engine and the two-stroke engine, achieving the supercharging of inlet pressure under the condition of structure compactness.

Part of force is offset for the circumferential and symmetrical distribution, and the stress on both sides of the main shaft of the piston engine is reduced effectively. The convex boss on the push rod bears force along the cam tangential, which reduces the force between piston and cylinder.

The simulation results show that the strength of the material meets the stress requirement between cam and roller, and the mechanism's operation is reliable.

The novel power transmission mechanism is circumferential distribution, which saves the space and makes its power density greater than the traditional engine. Simultaneously, increasing the number of peak and valley of the cam can increase the work frequency, and we can continue improving the engine's power density.

\section{ACKNOWLEDGEMENTS}

This paper is sponsored by National Natural Science Foundation of China (GN: 51175500).

My sincere gratitude first goes to $\mathrm{Mr}$. $\mathrm{Xu}$, my supervisor. Without his help, the completion of this thesis would have been impossible.

I would also like to express my thanks to my upperclassman Zhang Lei for his generous help and meaningful comments on the study.

\section{REFERENCES}

[1] Peng, Y., Deshi, W. \& Shuzong, W., 2007. Kinematics and dynamics of contrapositive cam engine. Torpedo Technology, (06): 13-16.

[2] Yongqing, L., Shuzong, W., Shijie, M., Yihui, C. \& Zhongjie, L., 2011. Dynamic simulation of the air-powered swashplate engine Chinese Journal of Mechanical Engineering, 44 (01): 243-248.

[3] Hougeng, L., 2004. Study status and development suggestion of supercharger. Vehicle Engine, (05): 1-3.

[4] Raman, P. \& Ram, N.K., 2013. Performance analysis of an internal combustion engine operated on producer gas, in comparison with the performance of the natural gas and diesel engines. Energy, 63. 


\section{MATEC Web of Conferences}

[5] Xu, X., Deng, H., Pan, C. \& Xu, H., 2014. A cam-quadrilateral mechanism for power transmission of a twin-rotor piston engine. Journal of Mechanical Science and Technology, 28 (3).

[6] Manufacture, Q.X.J.W.C.G.Y.J.T.M.K.L.O.M., Automation, Technology, Z.U.O., Hangzhou, 310014 \& China, Year. Stress and forces analysis between the cylinder bores and the pistons of roller radial piston pumped.^eds. The Fifth Lernational Conferneee on Fhiid Power Translnission and Control, Qinhuangdao, 6.

[7] Wang, H.P. \& Lin, A.C., 1989. Camex: An expert system for selecting cam-follower design parameters. The International Journal of Advanced Manufacturing Technology, 4 (1).

[8] Chen, H., Pan, C.-Y., Xu, H.-J., Deng, H. \& Han, C., 2014. Analysis on structural characteristics of rotors in twin-rotor cylinder-embedded piston engine. Journal of Central South University, 21 (6).

[9] Zou, T.-A., Xu, H.-J., Pan, C.-Y., Xu, X.-J. \& Chen, H., 2014. Mathematical modeling and analysis of thermodynamic processes in a twin-rotor piston engine. Journal of Central South University, 21 (11). 